\title{
Nevo sebáceo de Jadassohn. A propósito de un caso neonatal
}

\author{
Jadassohn sebaceous nevus: About a neonatal case \\ Lidia María Ortiz Cuquejo®e, Gloria C. Samudio Domínguez ${ }^{1,2} \oplus$, Regina Beatriz \\ Espínola ${ }^{2,3} \mathbb{C}$, Luis María Vera²® \\ ${ }^{1}$ Hospital Nacional de Itauguá. Itauguá, Paraguay. \\ ${ }^{2}$ Hospital General de Barrio Obrero. Asunción, Paraguay. \\ ${ }^{3}$ Centro Médico La Costa Lynch. Asunción, Paraguay.
}

\section{RESUMEN}

El nevo sebáceo de Jadassohn se presenta como una lesión hamartomatosa, de extensión variable. Puede estar presente al nacimiento y generalmente se localiza en cuero cabelludo. La zona presenta alopecia. En raras ocasiones puede malignizarse en la edad adulta. Se presenta un caso neonatal y se hace revisión de la literatura.

Palabras clave: Nevo de Jadassohn, neonatología.

\begin{abstract}
Jadassohn's sebaceous nevus presents as a hamartomatous lesion of variable extent. It can be present at birth and is generally located on the scalp. The area shows alopecia. In rare cases, it can become malignant in adulthood. A neonatal case is presented and a literature review is made.
\end{abstract}

Key words: Jadassohn nevus, neonatology.

\section{INTRODUCCIÓN}

El nevo sebáceo de Jadassohn es una lesión hamatomatosa congénita rara, no hereditaria. Se caracteriza por el crecimiento anormal de las estructuras pilo sebáceas y apócrinas ${ }^{(1)}$.

Se presenta al nacimiento y crece a medida que el paciente lo hace. De etiología desconocida, aunque algunos investigadores han enfocado al papilomavirus como posible agente etiológico ${ }^{(2)}$.

Durante la pubertad, debido al aumento de nivel hormonal, la lesión puede hacerse más evidente, expresándose como una lesión con hiperplasia de las glándulas sebáceas, folículos pilosos rudimentarios y, en la dermis profunda, glándulas apócrinas ectópicas dilatadas. En la epidermis se aprecia hiperplasia con hiperqueratosis, acantosis y papilomatosis.

Durante la edad adulta pueden desarrollarse distintas neoplasias sobre un nevo sebáceo, en su mayoría benignas: el tricoblastoma o el siringocistoadenoma papilífero son muy frecuentes. Aunque la incidencia de neoplasias malignas es menor del $5 \%$, algunos autores recomiendan la exéresis quirúrgica del nevo, que en lo posible debe diferirse hasta después de la pubertad ${ }^{(3)}$.

Correspondencia: Lidia María Ortiz Cuquejo, correo:lidia_ortiz123@hotmail.com

Conflicto de interés: Los autores declaran no poseer conflicto de interés

Recibido: 01/12/2020 Aceptado: 24/06/2021

DOI: https://doi.org/10.31698/ped.48032021009

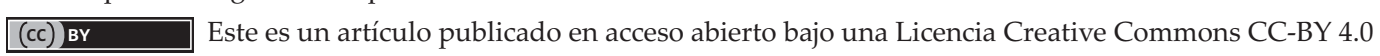


Esta lesión, cuyo abordaje es dermatológico, es esencialmente benigna. Este pronóstico a largo tiempo debe ser utilizado para dar tranquilidad a los padres, informando que los controles clínicos rutinarios de la lesión deben realizarse periódicamente ${ }^{(4)}$.

\section{CASO CLÍNICO}

Recién nacido de sexo masculino. Antecedentes maternos sin datos de interés. Nacido por vía vaginal. APGAR 8-9

Edad gestacional: 39 semanas, con peso de 3840 gramos, talla 53 centímetros, perímetro cefálico 35 centímetros. Signos vitales estables.

$\mathrm{Al}$ examen físico se observa una lesión en región temporal del cuero cabelludo, que presenta las siguientes características: presencia de dermatosis localizada en región temporal derecha siguiendo la línea de Blascko, constituida por una placa alopécica de aspecto verrugoso de 8 centímetros de largo por 3 centímetros de ancho, de coloración amarillo rosada, consistencia elástica inmóvil aparentemente indolora (figura 1 y 2). Sin otros datos de valor.

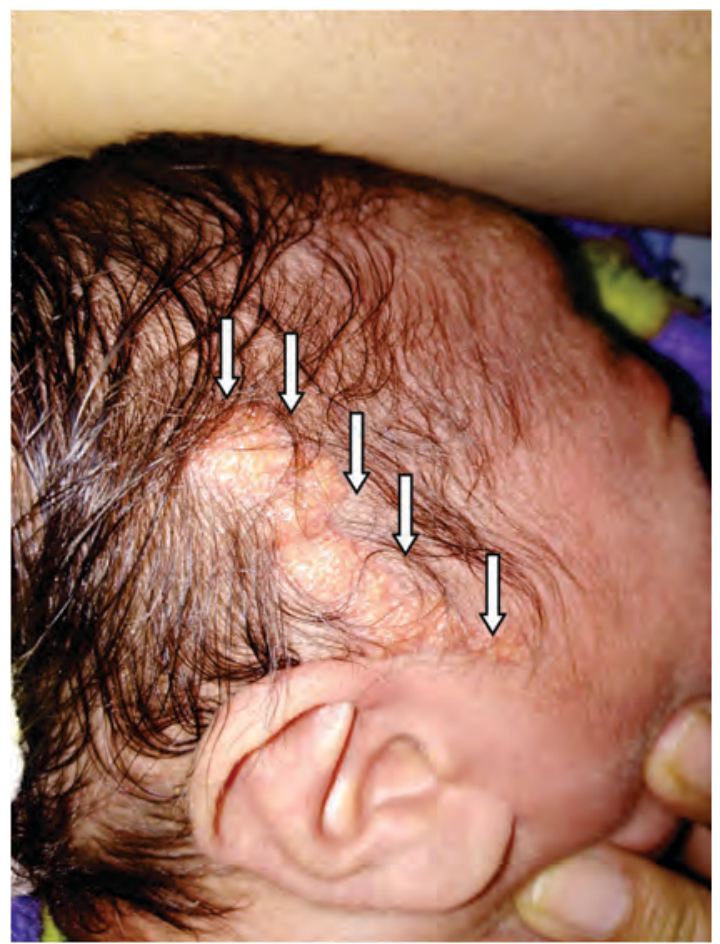

Figura 1. Puede observarse la lesión, de aspecto verrugoso, amarillento y alopécico.

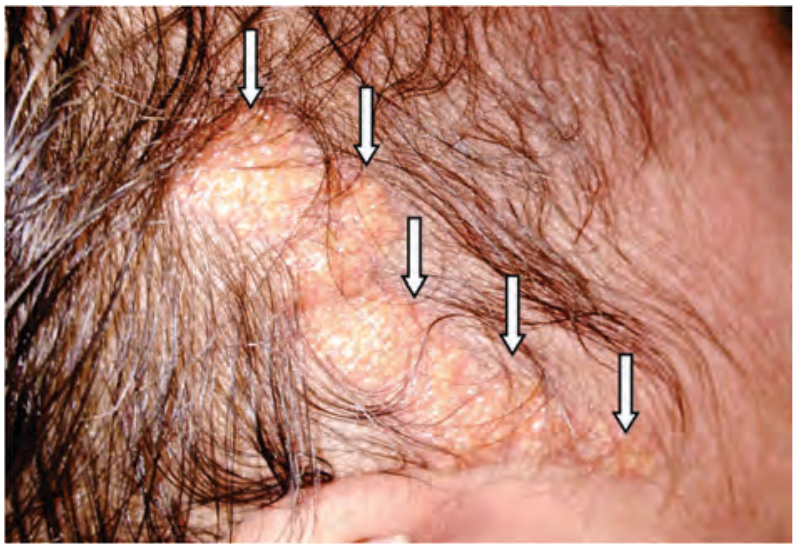

Figura 2. Acercamiento de la lesión.

No recibió tratamiento alguno y fue dado de alta para seguimiento de niño sano y consultorio de dermatología. El diagnostico fue confirmado por anatomía patológica donde informa, epidermis hiperqueratotica y papilomatosa, proliferación de tejido fibrovascular, atrofia de folículos pilosos, compatible con nevo de jadasshon.

\section{DISCUSIÓN}

El nevo de Jadashonn se presenta característicamente como una placa amarillo- anaranjada de hasta $10 \mathrm{~cm}$, que puede adoptar diversas formas. La superficie es en general lisa o levemente verrugosa ${ }^{(3)}$. Está presente en el $0,3 \%$ de los neonatos ${ }^{(1,4)}$.

Además de localizarse generalmente en el cuero cabelludo puede, raramente presentarse en cara tronco y extremidades ${ }^{(8)}$.

Es una lesión congénita, no hereditaria y de causa desconocida. Se caracteriza por crecimiento anormal de estructuras pilo sebáceas y de glándulas apócrinas ${ }^{(6)}$.

El abordaje es esencialmente de seguimiento, ya que la malignización de la lesión es extremadamente rara $^{(1)}$.

El uso de terapia foto dinámica para esta entidad aún está en desarrollo.

En menos del $5 \%$ de los casos se puede malignizar, en edad adulta. La escisión quirúrgica del nevo 
puede recomendarse en la adolescencia, ya que debido al aumento de las hormonas que ocurre en esta edad, puede haber transformación maligna ${ }^{(4,7)}$.

Es preciso hacer diagnóstico diferencial con el nevo epidérmico y la aplasia cutis. El nevo epidérmico tiene una epidermis hipertrófica e hiperqueratósica en común con el nevo sebáceo, pero los anexos dérmicos son normales. En cambio, la aplasia cutis muestra una epidermis atrófica y bandas colágenos horizontales típicos en la dermis.

\section{REFERENCIAS}

1. Alonso de Celada RM, Muruzabal F, De lucas Laguna R. Nevo sebáeo de Jadassohn An Pediatr (Barc). 2009; 70(4):391.

2. Moody MN, Landau JM, Goldberg LH. Nevus sebaceous revisited. Pediatr Dermatol. 2012;29(1):15-23.

3. Miereles A, Pereira M, Costa MJ. Nevo Sebáceo de Jadassohn em Recém-Nascido Acta Med Port. 2020; 33(4):288-288. doi: https://dx.doi.org/10.1016/j.an pedi.2008.11.019

4. Liancapi VP, Paiva MO. Sebaceous nevus of Jadassohn. Rev. Chil. Pediatr. 1996;67(2):84-86.

\section{CONCLUSIÓN}

El nevo de Jadasshon es una lesión benigna, que en etapas más avanzadas de la vida puede malignizarse, por lo que requiere control periódico y exéresis quirúrgica en algunos casos.

\section{CONTRIBUCIÓN DE AUTORÍA}

Todos los autores participaron en el diseño, recolección de datos, redacción del manuscrito y aprobación final.

5. Domingo J, Helwig EB. Malignant neoplasms associated with nevus sebaceus of Jadassohn. J Am Acad Dermatol. 1979; 1(6):545-56. doi: https://dx.doi.org/10.1016/s01909622(79)80100-0.

6. Chun K, Vázquez M, Sánchez JL. Nevus sebaceus: clinical outcome and considerations for prophylactic excision. Int J Dermatol. 1995; 34(8):538-41. doi: https://dx.doi.org/10.1111/j.1365-4362.1995.tb02948.x

7. Locke ST, Schaffenburg WC, Breedlove JP, Davis Ii DW, Bowden Iii LP, Royer MC. Squamous cell carcinoma with perineural involvement in nevus sebaceus. Cutis. 2019; 103(4):E17-E19. 